\title{
Entre o pioneiris mo e o impasse: a reforma paulista de 1920
}

Ana Maria Cavaliere

Universidade Federal do Rio de J aneiro

\section{Resumo}

Partindo das atuais preocupações com a melhoria da qualidade das escolas brasileiras de educação fundamental, o texto reexamina a reforma do ensino paulista de 1920, a qual explicitou o dilema político que atravessaria todo o século XX entre expansão e qualidade nos sistemas educacionais. Sua importância histórica tem sido registrada devido a seu pioneirismo na tentativa de inovar métodos de ensino e de racionalizar procedimentos administrativos.

Neste trabalho, aponta-se o conflito entre a proposta curricular da reforma em questão e sua prioridade declarada de alfabetizar em massa as crianças do estado em um curso primário por ela reduzido a dois anos de duração e duas horas e meia diárias de aula. A reforma inaugura de forma tecnicamente justificada a "solução" da redução do tempo de permanência das crianças na escola como condição para a ampliação da oferta de vagas, o que veio a se tornar uma prática generalizada nos sistemas educacionais de todo o país. São analisadas também as contradições nela reveladas entre as primeiras apropriações da pedagogia escolanovista e as tendências à simplificação e empobrecimento da escola pública brasileira

No momento atual em que a universalização do atendimento parece configurar um outro patamar a exigir novas soluções políticas para a obtenção da qualidade educacional, o texto enfoca retrospectivamente o tipo de solução política utilizada pela reforma paulista de 1920, destacando seus resultados imprevistos e indesejados, com vistas a um bom equacionamento dos desafios ora presentes.

\section{Palavras-chave}

Escola fundamental - Políticas educacionais - Jornada escolar Reformas do ensino.
Correspondência:

Ana Maria Cavaliere

Rua Delgado de Carvalho, 58/304

20260-280 - Rio de J aneiro - RJ

E-mail:anacavaliere@yahoo.com.br 


\section{Between the pioneering spirit and impasse: the 1920 São Paulo State reform}

Ana Maria Cavaliere

Universidade Federal do Rio de J aneiro
Contact:

Ana Maria Cavaliere

Rua Delgado de Carvalho, 58/304

20260-280 - Rio de J aneiro - RJ

E-mail:anacavaliere@yahoo.com.br

\section{Abstract}

Taking as a starting point the current concerns with the improvement of the quality of brazilian primary education schools, the text re-examines the reform of 1920 in São Paulo State, which made explicit the political dilemma that would last for the whole of the $20^{\text {th }}$ century between the expansion and the quality of school systems. The historical importance of that reform has been recognized in view of its pioneering attempts at innovating teaching methods and rationalizing management procedures.

The conflict is pointed out here between the curriculum proposals of the reform and its proclaimed priority of achieving widespread children literacy in the State of São Paulo when the first four years of primary education had been shortened by the same reform to a period of two years with two and a half hours daily attendance. The reform brings about in a technically justifiable way the "solution" of reducing daily attendance as a condition to increase places at school. Such measures then became generalized practices in education systems throughout the country. The present work also investigates the contradictions evidenced in that reform between the first assimilations of the New School pedagogy and the tendency to simplification and impoverishment of the Brazilian state school.

In the present moment when the universalization of education in Brazil seems to configure a new level of demand, requiring new political solutions to achieve high quality in education, the text focuses in retrospect the kind of political solution employed by the 1920 reform in São Paulo, highlighting its unanticipated and undesirable results, in the hope of contributing to a better resolution of the challenges faced today.

\section{Keywords}

Primary school - Educational policies - School daily attendance - School reforms. 
Dentro do contexto dos estudos sobre tempo e escola julgamos importante buscar, no processo de formação do sistema escolar brasileiro, os momentos em que se constituiu a tendência, que prevaleceu durante toda a segunda metade do século XX, de uma escola pública mínima, isto é, freqüentemente com cerca de apenas três horas diárias de aula em cinco dias semanais.

A escola mínima é, antes de tudo, o resultado de uma disposição latente em se associar à necessária massificação da Educação fundamental a redução de seu tempo e de sua qualidade. 0 resultado dessa disposição foi 0 atraso do poder público em acompanhar, tanto nos aspectos infra-estruturais como pedagógicos, o crescimento da população escolarizada no país, criando-se um quadro de falta de instalações e professores bem como de desarranjos provocados pelos altos índices de evasão e repetência. Quando e como se esboça essa tendência de solucionar pela escola mínima as demandas crescentes e inevitáveis por educação escolar? Que tipo de política foi a ela conduzindo? Estaremos no limiar de uma mudança em relação a esse quadro?

$\mathrm{Na}$ busca dessas respostas, revisitamos as reformas dos sistemas educacionais estaduais, realizadas na década de 1920 e, entre elas, a reforma paulista de 1920, que nos trou$x$ diversos elementos pertinentes às questões que hoje nos interessam: primeiramente a tensão entre qualidade e quantidade sob a qual foi se moldando, em nossa sociedade, o referido modelo de escola mínima, tão eficiente na criação do valor escola quanto ineficiente na consecução de suas tarefas básicas. Em segundo lugar, a relação entre educação de qualidade e modelo de jornada escolar, um ainda fraco objeto de reflexões político-pedagógicas.

A reforma do ensino paulista de 1920 , objeto deste artigo, foi emblemática e prenunciadora de um conjunto de problemas que vieram a enfrentar administradores e sistemas educacionais do país durante todo o século XX. Ela demonstra que a tendência à escola míni- ma se esboçou ainda no início daquele século, aos primeiros sinais de que a ampliação dos sistemas educacionais nos diversos estados brasileiros configurava-se como um fato inexorável.

A preocupação com a qualidade do trabalho pedagógico realizado nas escolas encontrava-se pressionada pela necessidade e urgência da quantidade. Nosso modelo econômico-social nunca permitiu um bom equacionamento do problema e transformou em dilema o que poderia ter sido um programa gradual de ampliação da escolarização. Até mesmo Anísio Teixeira, defensor da jornada diária completa e da educação primária de cunho formativo amplo, foi obrigado a contemporizar, quando Secretário de Educação e Cultura do Distrito Federal, nos anos 1930, com os três turnos diários da escola elementar, afirmando:

0 primeiro problema é, pois, o de oferecer mais educação. Ao administrador compete advertir se esse aumento de quantidade se faz com prejuízo substancial da qualidade. Desde que tal não se dê, só lhe cabe conceder 0 aumento pedido. É o que sucede hoje no Rio, com o regime de três turnos instalado em menos de um terço de suas escolas elementares. (Teixeira, 1997, p.198)

No momento presente, dados oficiais anunciam o fato de que a maioria das crianças brasileiras tem acesso à escola, ainda que nela permaneçam, em média, menos de seis anos, abaixo portanto da obrigatoriedade legal, sabendo - se ainda que, consideradas as desigualdades sociais e regionais, muitas delas permanecem tempo bem inferior a esse.

Para além dos dados estatísticos, um indicador de que há uma mudança no quadro de forças "quantidade x qualidade" parece ser a natureza das políticas públicas que vêm obtendo prioridade, bem como a repercussão que alcançam: são políticas voltadas para os problemas da evasão e repetência, tais como a organização dos "ciclos de aprendizagem" e a "bolsa-escola" - ambas procurando garantir a 
permanência das crianças na escola. A própria Lei de Diretrizes e Bases da Educação Nacional $(9394 / 96)$ indica políticas que pretendem reverter a baixa qualidade educacional tais como a formação em nível superior dos professores do primeiro segmento da Educação fundamental e 0 progressivo aumento da jornada escolar.

Quanto a esta última, vêm sendo realizadas experiências no país, não apenas de seu aumento progressivo mas também de implantação do horário integral. Além de algumas ocorrências pontuais em redes municipais de pequeno porte, dois programas de maior alcance se destacam: no Rio de J aneiro, o Programa Especial de Educação, responsável pela implantação, nas gestões estaduais de 1983/1986 e 1991/ 1994, de 500 Centros Integrados de Educação Pública (CIEPs). ${ }^{1}$ Em 2001, segundo levantamento do Inep, ${ }^{2} 19,4 \%$ dos alunos de Ensino fundamental público e privado do Rio de J aneiro estudavam em horário integral, sendo de 10\% a percentagem da capital. ${ }^{3}$ No Paraná, a prefeitura de Curitiba mantém em funcionamento 37 CEIs - Centros de Educação Integrada - que atendem em sistema de dia completo as crianças do primeiro segmento da Educação Fundamental. Os CEls absorvem hoje cerca de 35\% dos alunos matriculados na rede municipal.

Apesar de desativados, outros programas de grande porte como o Profic, ${ }^{4}$ em São Paulo, e os CAICs, ${ }^{5}$ em nível nacional, também apontavam nessa direção da busca da qualidade pelo aumento da jornada e das responsabilidades educativas da escola.

0 surgimento desse conjunto de políticas que pretendem um novo enfoque para a questão da qualidade na Educação fundamental dá-se no mesmo momento em que adquirem força política certas visões que transferem abusivamente lógicas de mercado para uma prática social - a educação pública obrigatória - que, por sua própria natureza (direito de todos, obrigação dos pais, da sociedade e do Estado), a elas não se adequa. Expressam essa visão, entre outras medidas, as políticas de premiação a professores ou escolas que vêm sendo implantadas em alguns estados. ${ }^{6}$
Conforme poderemos constatar, os conflitos entre a educação de qualidade para todos e as "soluções" de redução do tempo de escola para cada criança ou de prêmios visando o aumento da "produtividade" escolar já apareciam, guardadas as diferenças históricas, na reforma do ensino do estado de São Paulo de 1920. Ao recolocá-la em foco, analisaremos a concepção então vigente acerca dessa relação entre expansão quantitativa e qualidade, destacando as medidas ali tomadas com vistas à criação das vagas necessárias ao atendimento das crianças paulistas que, em sua maioria, ainda se encontravam fora da escola.

Outro aspecto também analisado é o contraste entre a proposta curricular da reforma e sua intenção prioritária de rápida alfabetização em massa, mostrando o conflito ali prenunciado entre as apropriações das concepções escolanovistas e as tendências ao que estamos aqui chamando de "escola mínima" na educação elementar pública brasileira.

Além dos textos da lei $n$ ㅇ 1.750 de 8 de dezembro de 1920 e do decreto no 3.356 de 31 de março de 1921 que regulamentam a reforma, utilizamos como material básico de análise uma série de artigos de Sampaio Dória, autor da reforma, escritos entre os anos de 1918 e 1923 e publicados no livro Questões de ensino.

1. Ao final de 1994 havia 507 CIEPs em funcionamento: 410 na rede estadual e 97 sob a responsabilidade do município do Rio de J aneiro (Ribeiro, 1995).

2. EC/INEP/SEEC - Censo educacional/2001.

3. Em 1999 o município do Rio de J aneiro possuía 60.170 alunos matriculados em regime de horário integral, o que correspondia a $10 \%$ dos alunos da rede e a 164 unidades escolares com regime de horário integral, correspondendo a $15 \%$ dos estabelecimentos da rede (Planilhas do E/DGED - 1999, não atualizada até fins de 2002).

4 . Por meio de convênio com as prefeituras, o Profic, instituído no estado em 1986, garantia recursos para a oferta de atividades às crianças nos horários em que não estivessem em aulas. 0 programa foi desativado em 1992

5. Criados em 1991, e reestruturados em 1993, os CAICs (Centros de Atenção Integral à Criança) continham, entre outras atividades, uma escola de dia completo.

6 .No Rio de J aneiro, o projeto Nova Escola, iniciado em 2000, oferece gratificação mensal aos professores que varia de acordo com o nível que suas escolas alcancem num processo avaliativo conduzido por instituição contratada. Em São Paulo, o sistema de bônus anuais aos professores e diretores, inaugurado em 2001, baseia-se no desempenho dos alunos de cada escola no exame oficial da rede estadual de ensino (Saresp), associado à assiduidade de seus professores e, inversamente, às taxas de evasão que a escola apresente. 
Nesse movimento que vai do presente ao passado, a intenção principal é fazer a avaliação sociopolítica do fato ocorrido no passado a partir das preocupações e temáticas do presente. 0 interesse sociológico em analisar os processos que levam à exclusão escolar de parte importante da infância e adolescência brasileiras conduziu-nos ao tema do tempo escolar como elemento fundamental na compreensão desses processos. A presença, na reforma em questão, de proposições radicais e originais relacionadas justamente ao tempo escolar, nos chamou a atenção e nos levou à reflexão aqui apresentada. $\mathrm{Na}$ reconsideração da reforma paulista de 1920, nos concentramos em sua concepção estratégica, em suas decisões políticas concretas e em seus efeitos práticos imediatos e de longo prazo, valendo-nos para isso de pesquisas históricas já realizadas sobre ela, tendo sempre como horizonte as ações políticas da atualidade na área educacional. Dessa forma, não empreendemos um estudo histórico original sobre a referida reforma mas tentamos aqui reproduzir o sempre fecundo encontro entre abordagens sociológicas e históricas.

\section{O contexto his tó rico da reforma}

A eleição do paraibano Epitácio Pessoa, em 1919, à Presidência da República significou uma mudança, ainda que relativa, no cenário político do país. A momentânea quebra no monopólio do poder político detido por São Paulo e Minas Gerais não chegou a romper a estrutura oligárquica de poder vigente mas provocou uma renovação em seu sistema de sustentação. Em outras palavras, modificaramse os métodos de manutenção do conservadorismo. As oligarquias dissidentes e os pequenos estados passaram a se articular, o que tornou o processo político eleitoral mais complexo. A prática conhecida como "política dos governadores", que consistia no mútuo e incondicional apoio entre poder central e governos estaduais, sofreu, com a eleição de Epitácio Pessoa, um primeiro revés. Iniciou-se um gradativo processo de centralização do poder e de fortalecimento do presidencialismo que culminaria com a revolução de 1930.

Paralelamente a esse processo político verificava-se uma maior diversificação da estrutura social. 0 crescimento e fortalecimento das classes médias e do proletariado geraram uma fase de conflitos e dificuldades para os governos das oligarquias. Uma sucessão de greves, entre elas a greve geral de 1917, em São Paulo, demonstrava que o movimento operário, então sob a forma de anarco-sindicalismo, tornara-se relevante. Somente no período de 1917 a 1920, ocorreram, no Rio de J aneiro e em São Paulo, mais de 200 greves operárias envolvendo cerca de 300 mil operários industriais (Fausto,1976).

A revolução socialista na Rússia e os movimentos operários em toda a Europa aqui repercutiam. Além disso, o agravamento das condições de vida da população, advindo dos problemas econômicos gerados pela Primeira Guerra Mundial, estimulava os movimentos e a organização da classe trabalhadora. Surgiram iniciativas operárias inclusive no campo escolar e educacional. Edgar Rodrigues (1972) chegou a levantar a existência de 25 escolas, até 1920 , mantidas por associações sindicais ou por militantes anarquistas em todo o país.

Associando-se o grande afluxo de imigrantes europeus verificado na época a este crescente movimento social, pode-se ter a medida da preocupação das elites com a questão do controle social e da afirmação da nacionalidade brasileira. 0 estrangeiro, além de todas as ameaças que trazia, pelo simples fato de ser um "diferente", trazia o "perigo" suplementar das ideologias revolucionárias. Era preciso, portanto, abrasileirar a todos, homogeneizar a nação.

É nesse contexto de imposição de mudanças à política tradicional que, em 1920, Washington Luís, eleito presidente do estado de São Paulo, escolhe como meta importante de sua gestão o combate ao analfabetismo. 
A definição dessa meta respaldava-se, conforme exposto acima, em pelo menos dois aspectos daquele momento político e social do país e especialmente do estado de São Paulo:

- o momento de instabilidade na política nacional, que poderia abalar a posição hegemônica de São Paulo na Federação, levando esse estado a se preocupar com o colégio eleitoral formado apenas por cidadãos alfabetizados - para as eleições vindouras;

- a preocupação com a unidade nacional e com o controle social, devido à imigração que se verificava de maneira intensiva em São Paulo associada ao processo de industrialização.

Para a direção geral da Instrução Pública do Estado, Washington Luís convida, em abril de 1920, o professor Sampaio Dória, que passa a elaborar a reforma do ensino, a qual se efetivaria na lei $n=1.750$ acima referida.

Sampaio Dória representava à época a corrente liberal, a qual defendia a igualdade de oportunidades e a evolução pela educação. Era vinculado à Liga Nacionalista de São Paulo e via 0 analfabetismo como incompatível com a civilização. Ademais temia - como boa parte da elite intelectual e política dos anos 1920 - pela integridade da Pátria, afirmando que

(...) a alfabetização do povo é, na paz, a questão nacional por excelência. Só pela solução dela o Brasil poderá assimilar o estrangeiro que aqui se instala em busca de fortuna esquiva. Do contrário, é o nacional que desaparecerá absorvido pela inteligência mais culta dos imigrantes. (Dória, 1923, p.16)

0 analfabetismo, encarado como "doença", pela intelectualidade da época, como o "maior inimigo da Pátria", nas palavras de Sampaio Dória, deveria ser combatido heroicamente. Tratava-se de uma cruzada moral.

Em São Paulo, após a República, constatou-se um crescimento proporcional de alfabetizados entre os anos de 1890 (191 alfabetizados por 1.000 habitantes) e 1920 (298 alfabetizados por 1.000 habitantes), mas o percentual de população alfabetizada, como se vê, alcançou apenas cerca de 30\% (Silva, 1988).

0 carro chefe da reforma foi a reestruturação do ensino elementar de modo a garantir vagas para as crianças paulistas que ainda se encontravam fora da escola. Surpreendia a escoIha de Sampaio Dória, um reformador, por Washington Luís, um homem do status quo. É de Lourenço Filho a explicação de que tal escolha deveu-se justamente ao fato de o educador ter defendido, à época, a possibilidade de uma soIução técnica salvadora. A simplificação que Sampaio Dória dera ao problema da extensão escolar necessária, mediante uma escola de dois anos, parecia sedutora aos governantes pelo aspecto de eficácia com pouca despesa, ou pequeno acréscimo de despesa (Antunha,1976, p.183). Em mensagem ao legislativo, em 1920, o presidente do estado afirmava que para criar as escolas necessárias às crianças paulistas que não as tinham, nos moldes então vigentes, seria necessário ampliar as despesas com educação de $17 \%$ para $40 \%$ dos gastos públicos gerais (Egas, E. apud Nagle, 1974, p. 207). 0 presidente considerava impraticável tal ampliação e encontrava um intelectual liberal, reformador, que afirmava a possibilidade da façanha otimizadora.

A convicção de Sampaio Dória no papel social da escola parecia vir ao encontro das necessidades e intenções do governo paulista. Essa identificação, entretanto, como ficou provado mais tarde, era bastante superficial. Os liberais de então, engajados num projeto antioligárquico de fortalecimento da nacionalidade e modernização da sociedade brasileira, estavam marcados pela proposta autoritária de higienização e regeneração física, moral e social da população brasileira, por meio da qual poderia ser alcançada a disciplina social necessária ao mundo moderno em construção. Para eles, a escola seria o elemento chave desse processo. Apesar do viés autoritário, o sentido geral de suas ações era reformista e progressista, ao contrário das forças oligárquicas no poder. 
As dificuldades que se sucederam eram previsíveis. Menos de um ano após ter assumido o cargo, o autor da reforma deixa a Secretaria de Instrução Pública. Segundo afirmou, foram as interpretações errôneas do governo sobre suas propostas de reestruturação que 0 levaram à exoneração. A reforma continuou sendo implementada por seu substituto, GuiIherme Kuhlmann, até 1925, quando então foi substituída pelo decreto $\mathrm{n} 03.858$ de 11 de junho de 1925.

\section{Distribuindo a escassez: a reforma em seus aspectos a dm in is trativos}

A primeira iniciativa da gestão Sampaio Dória foi a realização do recenseamento escolar. Revelou-se então um percentual de crianças sem escola bem maior do que os $50 \%$ imaginados, chegando a cerca de $70 \%$ (Antunha, 1976, p. 185). Além de orientar tecnicamente a reforma, o recenseamento serviu como respaldo à obrigatoriedade e padronização escolares que compunham o projeto republicano de homogeneização cultural da população. Além do combate ao analfabetismo, reagia-se ao surgimento de outros tipos de escola na sociedade paulista, tais como escolas privadas estrangeiras, escolas ligadas ao movimento anarquista e a entidades de cultura negra (Mate, 1991) com vistas à implantação de um determinado projeto de mudança.

Em meio às disputas políticas entre as visões oligárquica, liberal e das classes trabalhadoras emergentes as forças de expansão da escolarização no estado e no país se impunham. Entretanto, as forças da tradição pré-capitalista subsistiam. A quantidade de crianças ef etivamente fora da escola era grande, mas, como veremos adiante, o problema não se resumia à carência de vagas, abrangia também uma dimensão cultural relacionada à ainda frágil adesão de parcelas da população à escola.
No período, crescia no pensamento social reformador a expectativa de racionalização administrativa e de consolidação da responsabilidade público-estatal frente à educação primária. Renovadores como Sampaio Dória encarnavam as preocupações com a organização, a adequação de critérios às necessidades reais, enfim, com a busca de um melhor aproveitamento de recursos, em contrapartida aos antigos métodos baseados na influência política e na improvisação. A reforma incorporou esse espírito e, se isso a distingue como representante dos primeiros movimentos de afirmação e sistematização das idéias de mudança em educação, é, ao mesmo tempo, a origem de sua fragilidade política intrínseca: uma espécie de tecnicismo, estrategicamente ingênuo, tomou conta de suas propostas.

Do ponto de vista político mais imediato, essa busca por um novo modo de atuação administrativa estava subordinada às metas políticas do governo oligárquico e, mais diretamente, àquelas metas inspiradas pelos interesses eleitorais do estado. Havia ainda a motivação patriótica decorrente do resultado de pesquisa internacional realizada em 1920 e que colocava o Brasil em penúltimo lugar, em índice de alfabetização, entre as nações "civilizadas".

Assim, a reforma expressa em suas contradições a condição de estar ao mesmo tempo a serviço de um governo conservador, de um projeto de mudança nacionalista republicano e de um nascente movimento renovador em educação que buscava legitimar-se através da imagem da competência técnica, da eficiência e da modernidade, tendo como pano de fundo a direção histórica geral rumo à sociedade capitalista de massas.

A solução para a ampliação rápida do número de vagas nas escolas e para o pretendido combate ao analfabetismo foi a uniformização do ensino primário caracterizada pela redução de sua duração de 4 para 2 anos. Pretendia-se com isso a compatibilização e otimização da relação entre 0 número existente de professores e escolas e a quantidade de crianças escolarizadas e alfabetizadas anualmente. 
Após a implantação da reforma, a estrutura de ensino passou a compreender os seguintes níveis: ensino primário de dois anos (9 e 10 anos, o único obrigatório e gratuito); ensino médio de dois anos; ensino complementar de três anos (acoplado aos ginásios e escolas normais); ensino secundário especial (ginásios e escolas normais); ensino profissional; ensino superior.

Até essa época, não se podia falar propriamente da existência de um sistema padronizado pois as variações e a falta de coordenação eram grandes, mas, grosso modo, a estrutura anterior à reforma era composta de um nível primário de quatro anos gratuito e obrigatório, um nível pós-primário desmembrado em ginasial, normal e complementar, além dos níveis superior e profissional (Antunha, 1976).

As modificações no ensino primário pretendiam adequar à realidade 0 sistema anterior que era, segundo Dória, pretensioso e ineficaz:

\section{(...) a escola urbana de quatro anos tal} como tínhamos antes da Reforma, é a mais pura, a mais acabada ideologia delirante. É um aparelhamento que não alcança, nem pode jamais alcançar os fins que visava. (Dória, 1923, p. 299)

Antes da reforma, três tipos de escola compunham o sistema escolar público paulista: as escolas isoladas, de classe única multisseriada (em 1919 existiam 134 escolas isoladas na capital e 1.408 no interior); as escolas reunidas, compostas de agrupamento de classes multisseriadas, sem direção geral (em 1919 existiam 39 escolas reunidas, todas no interior); os grupos escolares, no topo do sistema, com quatro classes seriadas, com professores e salas de aula específicas para cada uma delas, direção geral e infra-estrutura de apoio (em 1919 existiam 31 grupos na capital e 154 no interior) (Antunha, 1976).

Pela reforma exigia-se de todas essas escolas a seriação, ou seja, a separação dos alunos

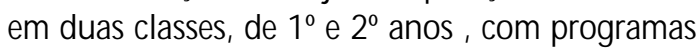

e espaços distintos. A promoção entre os níveis passaria a ser automática e a repetência vedada. 0 aluno que ao final dos dois anos de estudos não obtivesse 0 rendimento esperado estaria automaticamente excluído do sistema. No caso das escolas isoladas, havendo alunos suficientes, o professor responsável passaria a trabalhar em dois turnos de duas horas e meia diárias de aula, cada qual com um nível de adiantamento. A seriação e a separação das turmas representavam um avanço na qualidade. A diferenciação dos programas e idades, isto é, a especialização do trabalho escolar fortalecia a identidade profissional do professor e tornava a escola uma instituição mais forte.

0 percurso histórico cumpriu, ao longo desses 80 anos, uma espécie de retorno cíclico. A seriação anual rígida, que na época significou um avanço importante, tornou-se, na atualidade, um limite à realização de projetos pedagógicos inclusivos. Observa-se que, hoje, a seriação vem sendo questionada e paulatinamente substituída, em vários estados brasileiros, pelo sistema de ciclos de aprendizagem. A turma heterogênea, que à época representava a precariedade e indiferenciação do trabalho pedagógico, reaparece, hoje, em meio a novas práticas pedagógicas, com outros significados. Os avanços dos estudos psicopedagógicos e a incorporação ao pensamento educacional de autores como Piaget e Vigotsky deram ênfase aos processos sócio-interativos da aprendizagem escolar os quais não só admitem como se tornam mais ricos com o encontro entre diferentes níveis de aprendizagem.

Quanto à duração da jornada escolar - a possibilidade trazida pela reforma de 1920 de desdobramento do horário, anteriormente de 4 a 5 horas diárias, em dois turnos diários de duas horas e meia -, esta já era defendida por Sampaio Dória em 1918. Em carta aberta a Oscar Thompson, diretor da Instrução Pública de São Paulo, afirmava ser

(...) o tempo da eficiência. Ensinar, com proveito, 4 ou 5 horas a fio, é coisa dificílima, só possível, se for, em organizações 
vigorosas. Não se deve contar com a eficiência da terceira ou quarta hora seguida, sobretudo em se tratando de mulheres. (Dória,1923, p.21)

A redução do tempo de escola tornouse admissível visto que, apesar de a preocupação com a qualidade estar presente na reforma, o pensamento nela predominante foi ainda 0 da alfabetização como panacéia. Carvalho (1988) mostra que só a partir de meados da década de 1920 o "fetichismo da alfabetização" cedeu lugar aos movimentos em favor de uma concepção de educação integral. A solução da redução do tempo foi tecnicamente justificada por seu autor, com base na melhor qualidade do trabalho desenvolvido em tempo compacto e em turmas seriadas.

Merece ainda destaque, nessa linha da busca de uma racionalidade organizacional e da melhoria da qualidade do trabalho pedagógico, a proposta de gratificação às professoras em função do número de alunos que conseguissem alfabetizar por ano. Até então a média anual era de 12 crianças alfabetizadas por professor. A intenção era de, com a gratificação, duplicar ou mesmo triplicar essa média.

Ainda que o movimento renovador expresse 0 industrialismo e o estabelecimento da cultura urbana, as práticas educativas de inspiração "taylorista" tiveram, no início dos anos 1920, poucas chances de progresso. A pretensão de extensão, para todas as esferas da vida social, de minucioso controle técnico das pessoas e dos processos, encontrou muitos entraves. A distância entre a concepção ideal dos projetos reformadores que incluíam esse aspecto regulamentador da vida dos indivíduos e das instituições e o que de fato chegou a ser realizado nos sistemas educacionais revela essa dificuldade. Entretanto, as tentações behavioristas, intrínsecas à sociedade industrial de massas, já lá faziam uma aparição precoce. Hoje, 80 anos depois, associadas à lógica de mercado, tais tentações se fortalecem, sendo uma de suas expressões as já citadas políticas de prêmios a professores e escolas.
Quanto à questão nacional, a lei foi clara e minuciosa: as escolas particulares deveriam submeter-se às determinações da Diretoria de Instrução Pública. Deveriam assumir compromisso por escrito relativo a diversos pontos, tais como: respeito aos feriados nacionais, ensino do português (por professor brasileiro ou português nato), ensino de geografia e história do Brasil (por professor brasileiro nato), ensino dos cantos nacionais, proibição do ensino de língua estrangeira para crianças menores de 10 anos, abertura do estabelecimento às autoridades do ensino. As medidas acima visavam especificamente às escolas estrangeiras, implantadas em quantidade nas colônias de imigrantes, e não embutiam qualquer rejeição à escola privada em si. ${ }^{7}$

A nova lei previa também a reorganização dos concursos públicos para professores, a criação de 2 mil novas escolas isoladas primárias (omitida no decreto de regulamentação), a criação de 15 delegacias regionais de ensino, 0 aumento do número de inspetores escolares, a unificação curricular das escolas normais, a criação de escolas maternais junto às fábricas, a instalação de jardins de infância anexos às escolas normais, a criação de inspeção médicoescolar e a criação da Faculdade de Educação. Essas e outras medidas, se realizadas a contento, levariam obviamente a um grande aumento das despesas com educação.

Cedo começaram as atribulações de Sampaio Dória. 0 governo definiu, à sua revelia, que apenas as duas séries do ensino primário seriam gratuitas. Seus planos iniciais, entretanto, mantinham a gratuidade dos 4 anos, no caso dos grupos escolares, que ministrariam 2 anos de ensino primário e 2 de ensino médio, e até mesmo dos 3 anos das escolas complementares, posteriores ao médio, o que somaria 7 anos

\footnotetext{
7. A necessidade de ampliação do ensino privado era praticamente um consenso à época, defendida pelo próprio Sampaio Dória, e por inúmeros educadores, desde que esse ensino fosse supervisionado pelo Estado. No Inquérito promovido em 1926, pelo jornal $O$ Estado de S. Paulo, sobre a educação pública, três dos seis depoentes, além do próprio Fernando de Azevedo, que organizou e orientou o trabalho, apontavam a necessidade $e$ urgência de expansão da escola privada. (Azevedo,1926)
} 
de gratuidade. Dória conseguiu superar o problema garantindo gratuidade aos que comprovassem a impossibilidade de pagar as taxas e defendeu a solução afirmando que

0 dever do Estado em ministrar a educação popular é supletivo. Aos pais incumbe, preferencialmente, a educação aos seus filhos. Porque não o fazem, e tanto quanto baste, é que o Estado Ihe supre falhas. Não se compreende democracia em povo analfabeto, ignorante, incapaz. Logo, contribuir os que puderem, com uma taxa escolar pelos benefícios que os seus filhos recebem, não é um desses males tão graves que solape os fundamentos sociais, ou, mesmo prejudique a prosperidade geral. (Dória, 1923, p. 333)

0 trecho revela que apesar da convicção na importância do papel da educação escolar pública para a formação democrática e nacional, o pensamento reformador da época ainda comportava o entendimento de que era "supletivo" o dever do Estado em ministrar a educação primária. Ou seja, a responsabilidade última pela garantia dos direitos do indivíduo permanecia na esfera familiar e, portanto, privada. À época, a Constituição paulista já afirmava a obrigatoriedade e gratuidade do ensino primário, mas a realidade do sistema instalado encontrava-se muito distante da afirmação legal.

O segundo conflito com o governo, entretanto, levou Sampaio Dória à demissão. Tratava-se do estabelecimento, também à sua revelia, da obrigatoriedade escolar somente para as crianças de 9 e 10 anos, o que significava, na prática, a impossibilidade de escolarização para as de 7 e 8 anos. Transformava-se assim a solução da redução do ensino elementar para dois anos, que o autor da reforma redefiniu, posteriormente, como provisória e não generalizável, em solução definitiva e generalizada.

A proposta de redução do ensino primário de 4 para 2 anos, tal como apresentada originalmente por Dória, mostrava-se contraditória para fins de otimização de recursos. Como ela não previra, inicialmente, a redução concomitante do período de gratuidade e obrigatoriedade escolar, o resultado prático da redução do tempo se tornava duvidoso. 0 que poderia justificar a manutenção do mesmo período de qutro anos para a obrigatoriedade escolar e de até sete para a gratuidade, se a premência era garantir espaço nas escolas para o grande contingente de crianças paulistas que ainda se encontravam fora delas? Já que se tratava de criar vagas para todos, sem acréscimo de custos, a manutenção da obrigatoriedade e gratuidade para além dedois anos era, de fato, incoerente. A estratégia adotada pela concepção original da reforma de uniformização do sistema mostrava-se precária devido às profundas ambigüidades do pensamento reformador à época. Não por acaso, a reforma foi usurpada de seu autor e devidamente "reformada".

\section{Os efeitos prátic os e polític os da reforma}

Entre o grupo de profissionais da educação que despontava nas primeiras décadas do século, a solução de redução do ensino primário gerou inúmeras críticas e foi entendida por muitos como um retrocesso para o ensino paulista da época.

Já em 1923, o autor da reforma, ao comentar sua medida de maior repercussão, afirmava:

mas não se conclui daí que dois anos bastem ao preparo razoável do homem para a vida. Dois anos se aceitam, como recurso provisório, nas aperturas financeiras e retrações do crédito público. (Dória, 1923, p.77)

Dois anos após sua exoneração, o próprio Sampaio Dória já apresenta um discurso menos convicto perante a opção adotada.

Esse foi 0 aspecto mais controverso da reforma. A questão das vagas em São Paulo não 
se resumia ao problema da oferta mas, sim, e, talvez principalmente, conforme afirma Lourenço Filho em entrevista a Antunha (1976), ao problema da demanda. M esmo considerando-se que determinados segmentos da sociedade já desenvolviam lutas por mais escolas públicas e mesmo por concepções diferentes de escola (Mate, 1991), numa sociedade ainda em fase de industrialização a universalização da alfabetização e da escola era uma expectativa pretensiosa. Ainda que, num passe de mágica, se pudesse contar com vagas para todos, não era provável, a despeito da obrigatoriedade, que essas fossem preenchidas. É possível que Sampaio Dória tivesse essa compreensão e que nisso esteja a origem de sua contrariedade com a redução da obrigatoriedade de 4 para 2 anos de escolaridade. 0 cumprimento da obrigatoriedade estava longe de ser alcançado. Reduzi-la à faixa de 9 e 10 anos significava, na prática, excluir da escola crianças de 7 e 8 anos que tinham condições de ser por ela captadas. Ao mesmo tempo, não era possível garantir que a totalidade das crianças de 9 e 10 anos seria escolarizada.

Segundo Antunha, as medidas de controle e a aplicação de multas aos pais que não colocassem seus filhos de 9 e 10 anos na escola se intensificaram na vigência da reforma pela ação da inspeção escolar. Embora as exceções previstas em lei fossem muitas, houve nesse momento um esforço de inculcar hábitos escolares na população. 0 problema surge em relação às crianças que, aos 9 ou 10 anos, já estavam alfabetizadas, portanto, sem necessidade de freqüentar classes de alfabetização, e que não mais conseguiam vagas nas poucas classes remanescentes de $3 \circ$ e 40 anos transformadas em "ensino médio".

A redução do ensino primário de 4 para 2 anos foi o "calcanhar de Aquiles" da reforma. Posteriormente justificada como uma necessidade circunstancial de reorganização das escolas e classes, sua implementação prática estabeleceu a idéia de que 2 anos de escolarização eram suficientes para a massa da população, na medida em que eram suficientes para a alfabe- tização. A racionalização administrativa tentava impor-se às determinações de ordem política, histórica e ideológica mas, na prática, era reinterpretada por estas.

Sampaio Dória afirmou posteriormente que nem a regulamentação da lei, feita em 1921, após sua demissão, nem a aplicação desta respeitaram suas propostas. Ficou a reforma pressionada pelas críticas de educadores e políticos que a acusavam de promover a simplificação do ensino e retroceder em relação às conquistas da educação pública da época, pela impopularidade da redução drástica da gratuidade, pela exclusão escolar das crianças de 7 e 8 anos e pelo descontentamento do professorado com os deslocamentos dos postos de trabalho advindos da reorganização do sistema.

A reforma vigorou de março de 1921 a dezembro de 1925. Seu resultado negativo mais evidente foi o enfraquecimento dos grupos escolares, que eram consideradas as melhores organizações do sistema e que tiveram reduzido seu número de classes e de alunos. As escolas isoladas também tiveram uma redução em seu número de unidades, ocasionada pela transformação de muitas delas em escolas reunidas. 0 tipo de escola que mais cresceu no período foi justamente a escola reunida. Segundo afirmava Guilherme Kuhlmann, substituto de Sampaio Dória, aqueles estabelecimentos eram cômodos, de fácil administração e de baixo custo, e deveriam, na medida do possível, substituir os onerosos e complexos grupos escolares. Tais escolas mantiveram, no entanto, sua característica de escolas de segunda linha, extinguiram os $3 \circ$ e 4anos e, segundo Antunha (1976), foram a base, na década seguinte, para a aplicação das fórmulas de desdobramento, não apenas em dois mas em três ou mais turnos diários. A padronização, que pretendia vir acompanhada de uma maior especialização e profissionalização do sistema, acabou gerando um nivelamento "por baixo", trazendo problemas de desorganização e perda das referências de qualidade. 
Comparativamente aos outros estados que também realizaram reformas nos anos 1920, o crescimento do número de alunos matriculados no estado de São Paulo foi pequeno. Embora estudos comparativos mais criteriosos sobre as diversas reformas e seus respectivos resultados em termos do crescimento de matrículas precisassem ser feitos, os dados em estado bruto formam o seguinte quadro:

- Ceará (reforma de 1922 - Lourenço Filho): entre 1921 e 1923 o crescimento das matrículas no ensino primário foi de $65 \%$ (Nagle,1974);

- Bahia (reforma de 1925 - Anísio Teixeira): entre 1926 e 1929 o crescimento das matrículas no ensino primário foi de $44 \%$ (Nagle,1974);

- Minas Gerais (reforma de 1926 Francisco Campos): entre 1926 e 1929 o crescimento das matrículas no ensino primário foi de 39\% (Peixoto,1983);

- São Paulo (reforma de 1920 - Sampaio Dória): entre 1921 e 1924 o crescimento das matrículas foi de 16\% (Nagle,1974).

Em 1926, a liderança paulista na área educacional estava abalada. No inquérito realizado pelo jornal $O$ Estado de S. Paulo, Fernando de Azevedo afirma que essa unidade da federação encontrava-se em 5 ํlugar no país em relação às despesas proporcionais com educação. Fernando Azzi, um dos ouvidos, afirma que 0 estado perdeu não só a liderança organizativa mas também a teórica. (Azzi, F., apud Azevedo, $\mathrm{s} / \mathrm{d}) \mathrm{O}$ consenso entre os entrevistados do inquérito quanto à precariedade da educação pública paulista em 1926, isto é, após a vigência de cinco anos da reforma parece contraditório com o reconhecimento de todos de que a mesma representou um esforço modernizador e de alinhamento político com os ideais republicanos e democráticos. Se, num primeiro momento, a reforma foi criticada por aligeirar o ensino, cinco anos adiante, suas qualidade renovadoras e seu sentido democrático eram ressaltados.
0 tempo mostrou que a força do esquema oligárquico-elitista apropriou-se como quis da reforma. 0 governo interpretou e aplicou a reforma que, segundo Nagle (1974, p.192), introduziu "as primeiras e mais radicais alterações feitas nos sistemas escolares estaduais de todo o decênio dos vinte", da maneira que melhor lhe convinha. Interesses políticos imediatos tentaram reduzi-la, com a demissão de Sampaio Dória, aos marcos de uma estratégia político-eleitoral da elite conservadora paulista.

O conflito com o poder instituído e a exoneração precoce de Sampaio Dória, seguidos de seu alinhamento crescente com o pensamento escolanovista, que aprofundava suas discussões sobre a qualidade do ensino, possibilitou uma releitura, dele próprio e de outros educadores, a qual valorizou os aspectos técnicos inovadores do projeto original. Apesar dos resultados concretos pouco expressivos, a reforma de 1920 teve grande importância como uma referência, um modelo para os reformadores de outros estados, seja pelos avanços, seja pelos equívocos que apresentou. A reforma de 1925, que a substituiu, foi considerada um retrocesso, recebendo de Lourenço Filho a designação irônica de um movimento "rumo ao passado".

Resumidamente, as ambigüidades e fragilidades políticas da reforma assentavam-se nos seguintes pontos:

a) A superestimação da possibilidade de superar, num espaço curto de tempo, fatores socioculturais como a ainda fraca demanda da população pela escolarização e a dispersão da população rural.

b) 0 mau dimensionamento do tamanho do déficit, que tornou a solução de remanejar os recursos existentes absolutamente insuficiente.

c) A proposição de redução do ensino primário, que criou a possibilidade, bem-vinda à mentalidade oligárquico-aristocrática, de aligeirar a educação popular enfraquecendo o que de melhor existia no sistema, isto é, os grupos escolares. 
d) A associação da escolarização à simples alfabetização tornando a escola ainda mais inadequada à camada popular que a ela chegava e que, por estar distanciada da cultura letrada, necessitava de uma escola com concepção mais ampla de educação.

\section{Escolanovismo e aligeiramento: direções incompatíveis}

Conforme fica claro no artigo 103 do decreto de regulamentação, a base pedagógica da reforma é o método intuitivo, até então a mais avançada concepção educacional:

Nas escolas primárias, o método natural do ensino é a intuição, a lição de coisas, o contato da inteligência com as realidades que se ensinam, mediante a observação e a experimentação, feitas pelos alunos e orientadas pelo professor. São expressamente banidas da escola as tarefas de mera decoração, os processos que apelem exclusivamente para a memória verbal, a substituição das coisas e fatos pelos livros que se devem apenas usar como auxiliares de ensino.

Entretanto, segundo Carvalho (2000), o currículo da reforma de 1920 subverte 0 método intuitivo em vigor ao adotar o chamado "método de intuição analítica" enfatizando o desenvolvimento da "capacidade de conhecer" em detrimento do modelo de ensino intuitivo que vinha sendo desenvolvido desde a Reforma Caetano de Campos e que consistia em um percurso longo e enciclopédico, capaz de fazer com que o aluno, ao aprender, reproduzisse o processo de evolução do conhecimento.

Essa nova interpretação do método intuitivo tinha como base a urgência em alfabetizar e escolarizar a massa da população, além das já presentes "novas idéias em educação" ou idéias escolanovistas, que viriam a explodir, como um conjunto sistematizado, no decorrer da década de 1920.
0 programa das escolas elementares de 2 anos incluía as seguintes matérias: linguagem oral, leitura analítica, linguagem escrita, aritmética, geometria, geografia e história, ciências físicas e naturais, higiene, instrução moral e cívica, desenho, trabalhos manuais, música e ginástica.

Quanto à leitura, o programa proíbe a silabação e diz que a criança somente lerá sentenças e nunca sílabas ou palavras isoladas. Para história e geografia o programa inclui um trabalho baseado na experiência de vida do aluno, que deveria explorar a localidade em que mora, a localidade da escola e a vida de seus familiares. Em desenho, os trabalhos seriam feitos livremente, sem modelo, com temas da vida cotidiana.

Contraditoriamente, o programa traçado para os dois anos da escola elementar ainda é imenso aos olhos de hoje. Inclui análise sintática, números decimais, ângulos, área e volume, e todo um arsenal de informações de história e geografia que somente poderiam ser "adquiridas", nesse período de tempo, por meio da mais sistemática memorização.

Três anos após sua passagem pela Instrução Pública de São Paulo, Sampaio Dória, ao avaliar os resultados da reforma, já se mostrava mais familiarizado com as idéias propriamente escolanovistas. Ao fazer críticas à implantação da reforma aproveita para acentuar aspectos da lei de 1920 que lhe eram caros. Relembra a autonomia didática, a prática da logicidade (excluída do decreto de regulamentação), a nova concepção em educação cívica e a prática pedagógica nas escolas normais. Retomando o tema da autonomia didática, Dória afirma que

(...) com todas as cautelas de uma providência continuada e sistemática, a autonomia didática será o maior propulsor da grandeza e eficiência do ensino. Não é nunca o arbítrio da incompetência. É a liberdade de ação profissional dos competentes. 
A autonomia didática e a reestruturação das escolas normais levariam ao progresso da instrução pública, já que "a imposição do método contra a convicção íntima do profissional só pode gerar maus frutos". (Dória, 1923, p.303)

Ao diretor da instrução pública, inspetores e delegados regionais caberia a responsabilidade para que nesse espaço de liberdade acadêmica a "verdade científica" fosse respeitada. Ainda segundo Dória, por falta de orientação e definição de linhas gerais sobre as quais o professor deveria trabalhar, a autonomia didática teria degenerado e se transformado em anarquia.

A preocupação com a autonomia didática e com a formação dos professores estava no cerne da questão da qualidade do ensino. Expressava uma ambiciosa pretensão em relação ao ensino público e a seus professores que ultrapassava em muito a mera montagem de uma engrenagem alfabetizadora.

Sobre a proposta de educação cívica, Sampaio Dória explica que pretendeu substituir o ensino teórico, por ele definido como "aqui e ali, um curso prático de hipocrisia e o culto formal das aparências", pela aquisição de hábitos por meio da criação das associações de educandos. Para defender suas idéias, Sampaio Dória invoca as "repúblicas escolares" americanas fundadas por Wilson Gill, que defendia a "escola-cidade" como o remédio contra a apatia e a corrupção políticas. Aparecem aqui as idéias educacionais baseadas no estudo da psicologia humana, na co-participação do educando no processo educativo e na aprendizagem pela experiência. Da mesma forma, ao defender sua proposta de inclusão da prática pedagógica nos cursos normais, revela, mais uma vez, sua desconfiança em relação aos procedimentos didáticos discursivos e teóricos.

Ao defender a prática da logicidade, lamentando o fato do decreto-lei tê-la desconsiderado, Sampaio Dória afirma que esta deveria ser feita par a par com a matemática a fim de garantir "a sagacidade, o espírito de finura, o poder de atinar a verdade em meios de circunstâncias complexas que a obscureçam e a perturbem", já que a matemática garantiria apenas o raciocínio silogístico. A logicidade seria praticada em exercícios típicos, progressivos, que levariam os alunos à autonomia intelectual. Revela-se aqui a preocupação com aspectos metodológicos, com 0 "como aprender", com a diferenciação entre atividade intelectual mecânica e atividade intelectual compreensiva. Seu "método de intuição analítica", reforçando o aspecto da "capacidade de aprender", antecipava um dos pontos centrais do escolanovismo.

O currículo da reforma, em suas ambigüidades constitutivas, já apresentava a tentativa de responder às necessidades reais percebidas pelos educadores relativas à escolarização popular. A incompatibilidade entre o tipo de ensino vigente e a proposta de democratização da educação era evidente e as idéias escolanovistas emergentes ofereciam apoio teórico e estímulo para a ação concreta.

\section{Crises, reformas e mudanças}

A reforma paulista de 1920 vinha atender, por um lado, às necessidades do momento político que diziam respeito à implantação de novas formas de controle social e domínio político-partidário e, por outro, às necessidades históricas mais amplas que esboçavam uma reviravolta em direção à democracia burguesa moderna.

Coexistiam e se complementavam, em suas orientações político-administrativas e metodológicas, tanto influências positivistas quanto liberal-democráticas. 0 positivismo, ainda muito presente no país à época, correspondia à incorporação das regras da produção industrial ascendente à prática social. Nos aspectos administrativos da reforma essa influência aparece de modo muito claro em sua crença no planejamento, na neutralidade adminis- 
trativa e nas metas de eficiência. Também aparece, no currículo, na ênfase dada à "verdade científica", todos aspectos inseridos na visão mais geral de construção da nacionalidade. Já o liberalismo democrático se fazia presente pelo foco dado à democracia social e à formação da cidadania e cooperação por intermédio da escola, de acordo com o pensamento renovador europeu e norte-americano, como demonstra a invocação às repúblicas escolares de Wilson Gill.

Em síntese, a reforma de 1920 mesclava um conjunto de influências intelectuais e ideológicas da época que incluía tanto o ideário nacionalista de viés autoritário vinculado às idéias de "regeneração" das massas da população como 0 ideário liberal democrático nascente.

0 pensamento de cunho positivista bem como as idéias liberais em educação respondiam, por diferentes caminhos, à necessidade brasileira de racionalização dos processos sociais. Vinham ao encontro da tentativa de superação do modelo tradicional de nossa organização social e da construção de um Estado racional moderno.

A reforma paulista de 1920 é representante do que Nagle (1974) denomina de "entusiasmo pedagógico", típico das primeiras décadas do século. Um momento marcadamente político, cuja principal característica, segundo esse autor, era a preocupação quantitativista, de ampliação horizontal dos sistemas de ensino, ligada aos anseios da nova força política emergente, representativa do crescimento urbano industrial. Somente mais adiante, ainda segundo Nagle, na fase do chamado "otimismo pedagógico", as preocupações com a qualidade do ensino se tornariam predominantes, levando a uma despolitização do campo educacional. Divergindo em parte do quadro desenhado por Nagle, as preocupações da reforma de 1920 não se restringiam aos aspectos quantitativos e de fortalecimento institucional do sistema. É verdade que suas medidas de maior impacto tinham esse sentido mas, inúmeras outras, tanto administrativas como curriculares, apontavam em direção à busca da qualidade do ensino.
0 currículo da reforma revelava um pensamento especializado sobre as questões metodológicas da educação. A visão "salvadora" da alfabetização em massa encontrava-se minada pelas demais propostas que compunham 0 próprio texto da lei. Nesse caso, a forte politização que a envolve, não exclui uma desenvolvida preocupação técnico-pedagógica. ${ }^{8}$

A incorporação das grandes massas da população à escola exigia modificações profundas desta. Ou seja, as disparidades culturais, a permanência, especialmente no interior do estado, de modos de vida pré-capitalistas, não imediatamente dependentes da instrução escolar, requeriam uma escola formadora em sentido amplo. 0 aligeiramento era incompatível com a ampliação, a não ser do ponto de vista meramente contábil. Levava a uma escola ineficaz embora pudesse cumprir a função de valorizar o conhecimento escolar como moeda de ascensão social. Isso porque, a escola para todos, mesmo quando não atua ef etivamente na formação e ampliação de horizontes e oportunidades para os indivíduos, atua socialmente na criação de uma "moralidade" escolar, que põe em jogo valores simbólicos pelos quais se passa a excluir socialmente os que nela fracassam.

Coube à reforma de 1920 o ônus histórico de ter inaugurado a prática, muitas vezes reproduzida, da redução do tempo/qualidade escolar a que cada criança teria direito. Anísio Teixeira, trinta anos depois, por ocasião da inauguração do Centro Educacional Carneiro Ribeiro, em Salvador, citaria a reforma paulista como modelo desta concessão:

Foi, com efeito, nessa época que começou a lavrar, como idéia aceitável, o princípio de que, se não tínhamos recursos para dar a todos a educação primária essencial, deve-

8. A clivagem politização/quantidade e despolitização/qualidade desenhada por Nagle vem sendo questionada por Carvalho $(1988,2000 \mathrm{~b})$ ao defender a idéia de que no período do chamado otimismo pedagógico deuse uma repolitização em novos termos, a partir da substituição da alfabetização "salvadora" pelas concepções de educação escolar integral. 
ríamos simplificá-la até o máximo, até a pura e simples alfabetização e generalizá-la ao maior número. A idéia tinha a sedução de todas as simplificações. Em meio como o nosso produziu verdadeiro arrebatamento. São Paulo deu início ao que se chamou de democratização do ensino primário. Resistiram à idéia muitos educadores. Resistiu a Bahia antes de 30. Resistiu o Rio, ainda depois da revolução. Mas a simplificação teve forças para congestionar as escolas primárias com os turnos sucessivos de alunos, reduzindo a educação primária não só aos três anos escolares de Washington Luís, mas aos três anos de "meios- dias", ou seja, ano e meio, até na Grande São Paulo, aos três anos de "terços de dia", o que equivale realmente a um ano de vida escolar. Ao lado dessa simplificação na quantidade, seguiram-se, como não podia deixar de ser, todas as demais simplificações de qualidade. (Teixeira, 1994, p.173)

Só esse aspecto, embora ela contenha outros de grande relevância, faz da reforma paulista de 1920 um marco e justifica, nos parece, seu re- exame visando a uma contribuição ao entendimento dos processos que, na prática, foram conduzindo e constituindo o quadro presente da educação pública brasileira.

Tais processos, muitas vezes, são o resultado não previsto, pelos agentes sociais da mudança, de injunções políticas que terminam por reconduzir a realidade ao leito maior da estrutura social estabelecida. Mesmo quando percebidos e denunciados, nem por isso deixam de seguir esses caminhos "inesperados". Para além da percepção e denúncia, é o engenho político que, algumas vezes, consegue alterar esses rumos.

Sobre a reforma de 1920, por exemplo, intelectuais e educadores enxergaram a fragilidade da pretensão de alcançar os objetivos propostos apenas com a reorganização dos recursos existentes, ou de ampliar a oferta de ensino a partir da redução do tempo de escola para cada criança. 0 tema adquiriu relevância e, poucos anos após a reforma, Almeida J únior, J osé Escobar e Lourenço Filho questionaram, no já citado inquérito do Estado de $S$. Paulo, os próprios termos em que estava formulada uma de suas questões: "Educação integral para poucos ou educação simplificada para muitos? É válida a solução da redução do ensino primário?". Lourenço Filho responde afirmando que "a melhor solução provisória será, evidentemente, aquela que tornar mais fácil a execução posterior da solução definitiva, sem perda de nenhum elemento empregado ou conflito com os resultados já obtidos" (Lourenço Filho, apud Azevedo, s/d).

0 tipo de solução preconizada por Lourenço Filho não foi o que se generalizou. A dicotomia contida na questão se instalou. Os ideais da modernidade, que relacionam estreitamente educação das camadas populares e democracia, eram reelaborados naquele momento no país e adquiriam o perfil concreto, que ainda hoje predomina, de coexistência pacífica entre 0 direito formal pleno à educação de todos os cidadãos e a renitente inoperância e ineficácia dos sistemas educacionais implantados.

Crises e reformas educacionais são temas permanentes no Brasil e no mundo. Parecem fazer parte da natureza social da educação escolar. Elas evidenciam que nem sempre bastam ações racionais e competência técnica para se produzirem os resultados esperados. As inevitáveis tendências ou inércias da sociedade requerem imaginação e engenho político para que sejam vencidas.

A reforma paulista de 1920 pretendeu que a redução do tempo de escola de cada criança garantisse a expansão do sistema mas obteve, como resultado mais importante do que a própria expansão, a aceitação da redução do tempo e a perda da qualidade ali onde ela existia - nos grupos escolares. Na origem da distorção talvez esteja a concepção de educação ainda marcada, no pensamento mais progressista da época, pela pretensão de conformar a população a um tipo de sociedade almejada e, apenas secundariamente, pelo direito do indivíduo à cultura e à cidadania. 
Hoje, o aumento do tempo de escola com vistas à melhor qualidade pode, da mesma forma, obter, como resultado principal, a cristalização da prática educativa de baixa qualidade. Se a ampliação do tempo for entendida como algo passível de uniformização e essencialmente ou necessariamente positivo, o resultado poderá ser o inverso do pretendido. A ampliação do tempo de escola só será parte da busca pela qualidade se trouxer à pauta a discussão das formas de utilização do tempo, dos objetivos e possibilidades reais de um uso efetivamente enriquecedor desse tempo escolar. 0 aumento do tempo de escola sem o respectivo aumento da qualidade pode prestar um serviço às visões assistencialistas e/ou repressivas, que apenas incrementam o controle social sem garantir a formação da cidadania e a ampliação de horizontes culturais.

$\mathrm{Na}$ presente realidade educacional brasileira, a fórmula da escola mínima parece completamente esgotada. A expansão não pode mais justificá-la. Além da definição dos 200 dias letivos com carga horária mínima de 4 horas, a atual LDB, como já vimos, trouxe a indicação de aumento progressivo da jornada escolar no ensino fundamental, bem como de implantação do tempo integral. Estados e municípios já implementam políticas nessa direção.

Entretanto, como nos mostrou a experiência histórica aqui estudada, o tempo, em sua dimensão pedagógica, não é passível de padronização. A oferta de diferentes regimes de jornada escolar - parcial, integral, ampliada (atividades complementares no outro turno em alguns dias da semana) - dependerá sempre das demandas de cada realidade particular. A descentralização e multiplicidade de tipos de oferta parecem compor uma tendência a ser fortalecida.
Para além das contradições entre educação e emancipação, que revelam o caráter conflituoso dos interesses dos diferentes segmentos sociais na ampliação da escolarização, criou-se um consenso, já estabelecido e registrado em lei, em relação ao período de obrigatoriedade e aos tempos diário e anual mínimos necessários à escolarização fundamental. Já um consenso mais amplo quanto ao significado e aos componentes da "qualidade" em educação está longe de ser alcançado. Um dos poucos pontos consensuais evidentes concerne à percepção da baixa qualidade. M esmo eliminando-se preconceitos e desinformação em relação ao sistema público, prevalece a avaliação de que falta qualidade à atual escola fundamental pública brasileira.

Isso nos mostra que o impasse político explicitado pela reforma paulista de 1920, que viria a atravessar todo o século $X X$, ou seja, o processo de antagonização entre a possibilidade da ampliação quantitativa e a garantia da qualidade, chegou a termo exatamente da forma como foi esboçado: a expansão se deu e a qualidade não veio. A partir daqui, ações políticas visando a qualidade, caso incorporem o legado que a história nos deixou, terão que discutir a questão do tempo escolar, sua ampliação e ordenação, levando em consideração, primordialmente, os direitos e necessidades das crianças e jovens em relação ao aprendizado em seu sentido amplo. Outras motivações relacionadas seja à contenção da transgressão juvenil, seja aos interesses do mercado de trabalho ou ao conforto das famílias, embora relevantes, precisam subordinarse àquela, sob pena de, mais uma vez, produzirem-se ef eitos indesejados.

\section{Referências bibliográ fic as}

ANTUNHA, H.C.G. A Instrução Pública no Estado de São Paulo: a reforma de 1920. São Paulo: FEUSP, 1976. (Estudos e Documentos, v.12).

AZEVEDO, F. A educação na encruzilhada. São Paulo: Melhoramentos, [s.d.]. 
CARVALHO, M.M.C. Notas para a reavaliação do movimento educacional brasileiro (1920-1930). Cadernos de Pesquisa, São Paulo, n. 66, p. 4-11, ago. 1988.

Reformas da Instrução Pública. In: Lopes, E.M.T.; Faria FILHo, L.M.; VeIGA, C.G. (Orgs.). 500 anos de educação no Brasil. Bèlo Horizonte: Autêntica, 2000 (a).

. 0 debate sobre a identidade da cultura brasileira nos anos 20: 0 americanismo de Anísio. In: SmolkA, M.L.B.; Menezes, M. C. (Orgs). Anísio Teixeira: provocações em educação. Campinas: Autores Associados, 2000 (b).

DÓRIA, S. A reforma de 1920 em São Paulo. São Paulo: Monteiro Lobato \& Cia. Editores, 1923. (Questões de ensino, v.1)

FAORO, R. Os donos do poder. Porto Alegre: Globo, 1976. v.2.

FAUSTO,B. Trabalho urbano e conflito social (1890-1920). São Paulo: Difel, 1976.

MATE, C.H. Dimensões da educação paulista nos anos 20: inquirindo, reformando, legitimando uma escola nova. 1991. Dissertação (Mestrado) - Pontifícia Universidade Católica de São Paulo, São Paulo, 1991.

NAGLE, J. Educação e sociedade na Primeira República. São Paulo: EPU/MEC, 1974.

PEIXOTO, A.M.C. Educação no Brasil anos vinte. São Paulo: Edições Loyola, 1983.

RIBEIRO, D. 0 novo livro dos CIEPs. Carta, Brasília, 1995.

RODRIGUES, E. Nacionalismo e cultura social (1913-1922). Rio de J aneiro: Ed. Laemmert, 1972.

SILVA,T.R.N. Conteúdo curricular e organização da educação básica: a experiência paulista. São Paulo: PUC, 1988. Mimeografado.

TEIXEIRA, A. Educação não é privilégio. Rio de J aneiro: UFRJ , 1994.

. Educação para a democracia. Rio de J aneiro: UFRJ , 1997.

SÃO PAULO (Estado) Lei № 1.750, de 8 de dezembro de 1920. Reforma a Instrução Pública do Estado.

SÃO PAULO (Estado) Decreto № 3.356, de 31 de maio de 1921. Regulamenta a Lei № 1.750, de 8 de dezembro de 1920, que reforma a Instrução Pública.

Recebido em 27.06.02

Aprovado em 29.10 .02

Ana Maria Cavaliere é professora da Faculdade de Educação da UFRJ . Socióloga e doutora em Educação pela FE/UFRJ . Participa do Núcleo de Estudos Escola Pública de Horário Integral UNIRIO/UFRI . Recebeu o Prêmio J ovem Cientista Faperj/ 2000. É autora e co-organizadora do livro Educação Brasileira em Tempo Integral, Ed.Vozes, 2002. última publicação: "Educação integral: uma nova identidade para a escola brasileira", Educação e Sociedade, n.81, dez 2002. 